\title{
Atributos dos solos do complexo petroquímico Comperj em função de variações litotípicas, da paisagem e do uso atual
}

\author{
Joao Bosco Vasconcellos Gomes', Gustavo Ribas Curcio ${ }^{1}$, Renato Antonio Dedecek², Michele Ribeiro Ramos² \\ ${ }^{1}$ Embrapa Florestas, Estrada da Ribeira, Km 111, CP 319, CEP 83411-000, Colombo, PR, Brasil \\ ${ }^{2}$ Projeto Biomas - CNA/Embrapa Florestas, Estrada da Ribeira, Km 111, CP 319, CEP 83411-000, Colombo, PR, Brasil
}

\author{
"Autor correspondente: \\ joao.bv.gomes@embrapa.br \\ Termos para indexação: \\ Florestas secundárias \\ Pastagens \\ Rio de Janeiro \\ Index terms: \\ Secondary forests \\ Pastures \\ Rio de Janeiro
}

Histórico do artigo:

Recebido em 17/07/2013

Aprovado em 04/03/2014

Publicado em 04/04/2014

doi: 10.4336/2014.pfb.34.77.567
Resumo - A implantação do Comperj (complexo petroquímico da Petrobras e de empresas parceiras no município de Itaboraí) envolve um grande impacto ao meio natural, sendo ao mesmo tempo uma oportunidade para ações de compensação ambiental. O presente trabalho procurou caracterizar a química e a mineralogia dos solos da área do Comperj, considerando a granulometria e a morfologia dos solos, como também os diferentes materiais de origem, as posições de paisagem (terços superior, médio e inferior de encosta e terraços da planície) e as diferentes coberturas vegetais atuais. As paisagens de planície e encosta apresentam diferenças de comportamento de vários atributos químicos do solo, além daquelas associadas à própria paisagem (relevo e regime hídrico). Nas encostas também ocorrem diferenças de comportamento entre as amostras de solo, em função da origem litotípica e da fitofisionomia atual. Os sítios de floresta e pastagem das encostas apresentam comportamento diferenciado para vários atributos químicos, ressaltando-se, entretanto, que os valores médios de $\mathrm{C}$ orgânico não diferiram entre os dois grupos. A mineralogia de todos os solos é extremamente caulinítica, observando-se poucas diferenças entre os grupos dos litotipos. A consistência muito a extremamente dura no topo do horizonte B foi descrita para perfis de solo de encosta dos dois grupos de material de origem (Proterozóico e Terciário).

\section{Chemical and mineralogical soil atributes from Comperj area due to variations in lithotype, landscape position and vegetation cover}

\begin{abstract}
Establishing Comperj (petrochemical complex Petrobras and partner companies at Itaboraí city, Rio de Janeiro State, Brazil) involves a great impact on natural environment, while it is an opportunity for actions of environmental compensation. The objectives of this study were to characterize soil chemistry and mineralogy of Comperj area, based on landscape, particle size distribution and soil morphology, also considering different parent materials, landscape positions (shoulder, backslope and footslope at the hillslope and toeslope at floodplain) and vegetation cover groups. Different landscape positions, comparing toeslope and average hillslope, have differential behavior on several chemical attributes, besides those associated with landscape position itself (topography and water regime). Along the hillslope, differences on surface soil samples also occurred, considering studied attributes, among different parent materials and vegetation cover groups. Sites of both vegetation cover groups (forest and pasture) along the hillslope showed differences on many chemical attributes, except for organic $\mathrm{C}$ average values that were not differentiated among them. Soil mineralogy on all samples was extremely kaolinitic and there were small differences among parent material groups. Soil consistencies observed were very to extremely hard on both soil parent material groups, Proterozoic and Tertiary.
\end{abstract}




\section{Introdução}

A implantação do Comperj, complexo petroquímico da Petrobras e de empresas parceiras no Município de Itaboraí, $\mathrm{RJ}$, envolve um grande impacto ao meio natural. Esses impactos se distribuem em todas as fases do empreendimento: planejamento, construção operação e desativação.

Do ponto de vista da cobertura vegetal (agrícola e florestal), o maior impacto tem origem na fase de construção, principalmente na obras de terraplanagem, com aproximadamente $25 \mathrm{~km}^{2}$ de movimentação de terra e escavações. É a maior obra de terraplanagem do Brasil, superando Itaipu e outras hidrelétricas (Barreiro, 2014). A supressão desse volume de vegetação torna essencial ações de compensação ambiental associadas à revegetação. No relatório de impacto ambiental do empreendimento estão previstas a recuperação de áreas degradadas e a implantação de um corredor de vegetação na bacia hidrográfica local (rios Macacu e Caceribu), sendo que essas ações se darão nas áreas do empreendimento não envolvidas pela matriz industrial e em áreas públicas e privadas do entorno (Relatório ..., 2014). Para essas ações, os estudos de solos ajudam a definir estratégias de regeneração de áreas de floresta e, igualmente importante, alternativas agroflorestais para melhoria das condições de vida da população rural do entorno.

O presente trabalho procurou caracterizar a química e a mineralogia dos solos da área do Comperj, considerando a granulometria e a morfologia dos solos, como também os diferentes materiais de origem, as posições de paisagem (terços superior, médio e inferior de encosta e terraços da planície) e as diferentes coberturas vegetais atuais.

\section{Material e métodos}

\section{Área de estudo}

Aárea do Comperj está inserida em região sedimentar da Bacia da Guanabara, a qual faz parte do Rift da Guanabara (Almeida, 1976). As paisagens de encosta são formadas por pacotes estratigráficos metamórficos do Proterozóico (embasamento cristalino) e volumes correlativos sedimentares do Terciário da Formação Macacu (Lima et al., 1996), com ampla predominância dos últimos (Curcio et al., 2009). Completam a área sedimentos aluviais do Holoceno, pertencentes às bacias dos rios Macacu e Caceribu, formando as paisagens das planícies, onde prevalecem solos com regimes de umidade hidromórficos. Dentro da área do projeto convivem planícies e encostas sob pastagens e sob florestas secundárias em estágios iniciais de regeneração.

A área do Comperj está localizada no Município de Itaboraí, RJ, nas partes baixas das bacias dos rios Macacu e Caceribu. A área de estudo corresponde a porção leste da área total do empreendimento, onde a Embrapa coordena ações de pesquisa e revegetação de fitotipias arbóreas locais (florestas ombrófilas densas de terras baixas, aluvial e submontana, dependendo da posição de paisagem), iniciando a implantação de um corredor ecológico que pretende avançar em direção às partes elevadas da bacia do rio Macacu (Bonnet et al., 2009). São aproximadamente 1.000 ha definidos pela Petrobras, limitados com a área de terraplanagem e de construção da planta do complexo e com áreas externas ao empreendimento, de comunidades locais (Figura 1). A região de Itaboraí apresenta um clima tropical relativamente uniforme durante todo o ano. A precipitação média anual é de aproximadamente 1.500 $\mathrm{mm}$, com forte concentração entre os meses de novembro e abril. $\mathrm{O}$ verão também concentra as maiores médias de temperatura, chegando aos $26^{\circ} \mathrm{C}$ no mês de janeiro, decrescendo até o mês de julho, oscilando em torno de $24^{\circ} \mathrm{C}$ (Resende et al., 2009). O empreendimento localizase entre a Baía de Guanabara e as encostas da Serra dos Órgãos, o que pode influenciar a circulação de umidade evaporada da baía e de nuvens e chuvas convectivas devido ao efeito orográfico da Serra.

\section{Desenho experimental e perfis amostrados}

Os solos foram agrupados por origem litotípica, posição na paisagem e uso atual da terra (Tabela 1). As amostragens são oriundas de 48 trincheiras abertas na área de estudo. A declividade do terreno foi inserida como atributo na discussão dos agrupamentos.

\section{Amostras consideradas e análises de solos}

As amostras deformadas foram secas ao ar e passadas em malha $2 \mathrm{~mm}$ para obtenção da fração terra fina seca ao ar (TFSA).

Na discussão dos dados químicos, foram aproveitados os dados dos horizontes genéticos superficiais (horizontes A, Ap) e um caso de horizonte subsuperficial BA, em um perfil com fase erodida. Foram determinados $\mathrm{pH}$ em $\mathrm{CaCl}_{2}$, granulometria, $\mathrm{C}$ orgânico $(\mathrm{CO}), \mathrm{P}$ assimilável (Pas) e cátions do complexo sortivo ( $\mathrm{Ca}, \mathrm{Mg}, \mathrm{K}, \mathrm{Al}$ e H), conforme indicados por Claessen (1997). A soma de bases (SB), a capacidade de troca catiônica (CTC), a saturação por bases (V\%) e a saturação por $\mathrm{Al}(\mathrm{m})$ foram calculadas a partir das determinações do complexo sortivo. 


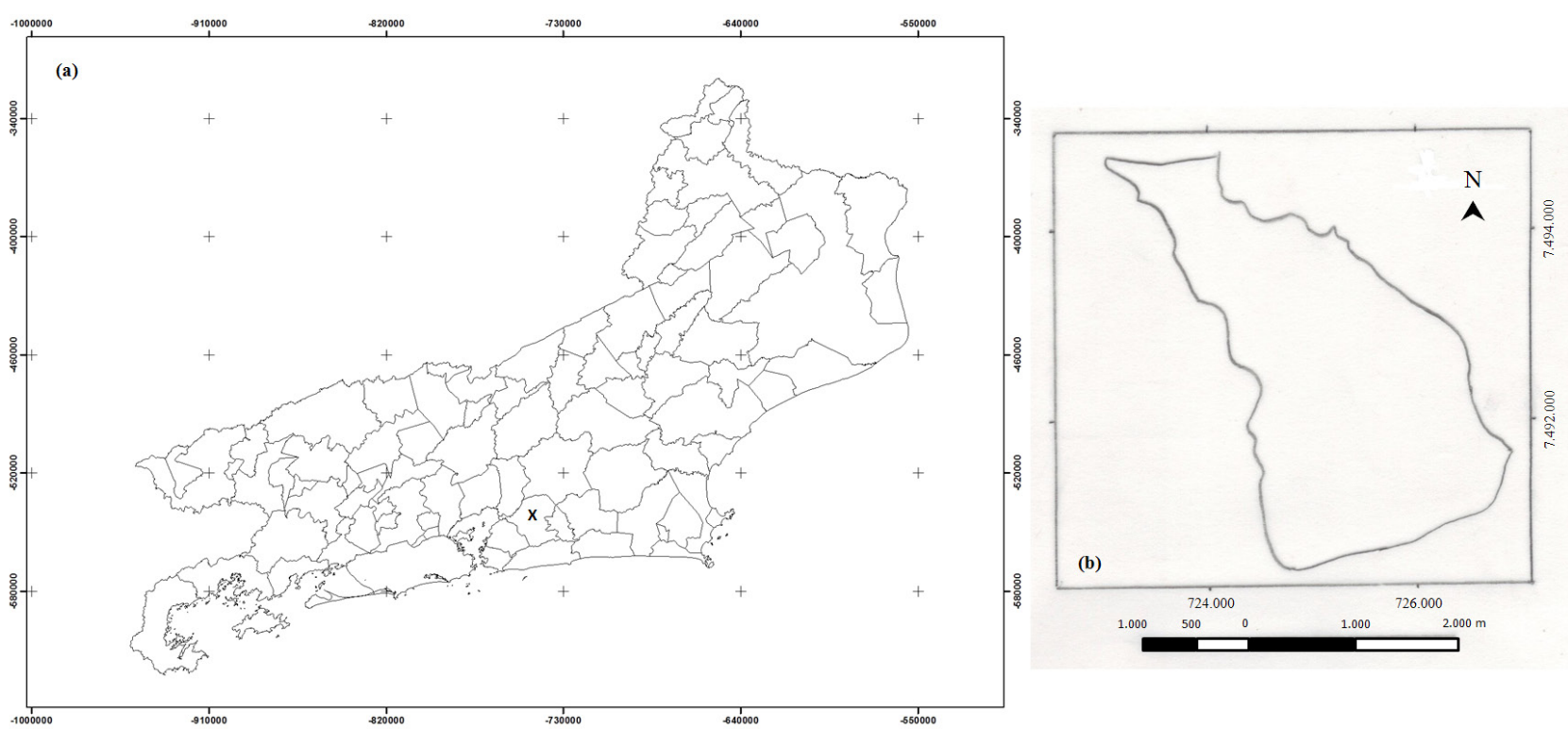

Figura 1. Mapa da divisão municipal do Estado do Rio de Janeiro (projeção Lambert Conforme Conica), com a localização aproximada do Comperj (X) no Município de Itaboraí (a); e porção leste do Comperj (projeção UTM), que corresponde a área do projeto Embrapa/Petrobras (b).

Tabela 1. Aspectos levados em consideração no agrupamento das amostras.

\begin{tabular}{|c|c|c|c|}
\hline Unidade de paisagem & Origem litotípica & Posição na paisagem & Uso da terra \\
\hline Encosta $-\mathrm{EN}^{1}$ & Proterozóico - PR $(\mathrm{n}=18)$ & terço superior de vertente $(\mathrm{n}=13)$ & floresta secundária - FL $(n=15)$ \\
\hline \multirow[t]{2}{*}{$\left(\mathrm{n}=38^{2}\right)$} & Terciário - TE $(\mathrm{n}=20)$ & $\begin{array}{l}\text { terço médio de vertente } \\
\qquad(\mathrm{n}=12)\end{array}$ & pastagem abandonada - PA $(\mathrm{n}=23)$ \\
\hline & & $\begin{array}{l}\text { terço inferior de vertente } \\
\qquad(\mathrm{n}=13)\end{array}$ & \\
\hline \multirow{4}{*}{$\begin{array}{c}\text { Planície - PL } \\
(\mathrm{n}=10)\end{array}$} & Holoceno $(n=10)$ & terraço fluvial $(\mathrm{n}=3)$ & \\
\hline & & bacia de inundação $(\mathrm{n}=5)$ & regeneração $(\mathrm{n}=2)$ \\
\hline & & dique marginal $(\mathrm{n}=1)$ & pastagem $(\mathrm{n}=8)$ \\
\hline & & base da encosta $(n=1)$ & \\
\hline
\end{tabular}

${ }^{1}$ Abreviaturas como usadas no texto. ${ }^{2} \mathrm{n}$ - número de trincheiras de solo em cada situação.

Para a discussão da mineralogia, utilizaram-se amostras subsuperficiais (horizontes genéticos B e C) de perfis selecionados nas encostas e na planície. Nas encostas foi selecionada uma elevação de cada litotipo (PR e TE), com um perfil por posição na vertente (terços superior, médio e inferior), assim classificados: cinco perfis de Latossolos Amarelos Distrocoesos típicos (três em vertente sustentada por TE e os terços médio e inferior da vertente sustentada por PR) e um de Latossolo Vermelho-Amarelo Distrófico típico (perfil do terço superior da vertente sustentada por PR), realçando que os Latossolos dominam as áreas de encostas do universo estudado. Na planície foram amostrados dois perfis, um representando os regimes de umidade hidromórfico (Gleissolo Tb Distrófico plíntico) e outro o regime semi-hidromórfico (Cambissolo Flúvico Tb Distrófico gleissólico), que se localizam, respectivamente, na bacia de inundação e no terraço fluvial. Para as análises de difração de raios-X (DRX), foram separadas amostras de argila a partir da TFSA por sedimentação após dispersão com NaOH 1,0 mol.L-1 (Claessen, 1997). As determinações de $\mathrm{Fe}, \mathrm{Al}$, Ti, $\mathrm{P}$ e Si foram obtidas após tratamento da TFSA com $\mathrm{H}_{2} \mathrm{SO}_{4}$ 1:1 (volume). As relações moleculares $\mathrm{SiO}_{2} / \mathrm{Al}_{2} \mathrm{O}_{3}(\mathrm{Ki}), \mathrm{SiO}_{2} /\left(\mathrm{Al}_{2} \mathrm{O}_{3}\right.$ $\left.+\mathrm{Fe}_{2} \mathrm{O}_{3}\right)(\mathrm{Kr})$ e $\mathrm{Al}_{2} \mathrm{O}_{3} / \mathrm{Fe}_{2} \mathrm{O}_{3}$ foram calculadas. Foram confeccionadas lâminas para a DRX da fração argila 
desferrificada com ditionito-citrato-bicarbonato (Mehra \& Jackson, 1960). As análises de DRX e ataque sulfúrico foram realizadas em laboratórios do DCS-UFLA.

\section{Análises estatísticas}

Os dados foram submetidos à análise de variância multivariada, testando efeito dos grupos de origem litotípica, de posição de paisagem e de uso da terra. Testes univariados foram usados para separar as médias significativamente diferentes na comparação de cada grupo. Foi determinada e discutida a correlação linear entre os diferentes atributos de solo. Uma análise de componentes principais (ACP) foi desenvolvida, considerando aqueles atributos com bons índices de correlação, com o intuito de realçar as diferenças de comportamento dos sítios das vertentes sob diferentes usos da terra (dados padronizados pela média dentro de cada variável).

\section{Resultados e discussão}

\section{Atributos químicos dos horizontes superficiais}

Análises de correlação de 14 atributos (13 de materiais de solo superficial e a declividade local) resultaram em correlações significativas $(\mathrm{p}<0,05)$ em 52 de 91 pares de atributos (Tabela 2). Vários atributos formaram até 10 pares de correlação significativa. A grande surpresa foi a ausência de correlações tradicionais entre $\mathrm{CO}$ e alguns atributos, principalmente teor de argila e CTC (Feller \& Beare, 1997; Zinn et al., 2007). A CTC foi dependente da acidez extraível $(\mathrm{H}+\mathrm{Al}, \mathrm{r}=0,97, \mathrm{p}<0,01)$ e não apresentou correlação significativa com a SB.

Um modelo linear multivariado (MLM) mostrou resultado significativo para a comparação das paisagens de planície e encosta $(\mathrm{p}<0,01)$, no total das amostras $(n=48)$. Considerando apenas as amostras de encosta $(n=$ 38), o MLM mostrou resultado significativo $(\mathrm{p}<0,01)$ para origem litotípica e uso atual da terra. Dessa forma, os atributos avaliados não mostraram diferenças significativas em função da posição de paisagem dos solos na encosta, descartando a importância dessa discussão para os atributos analisados, o que não desmerece a influência dessa distinção, principalmente quanto à diferenciação do regime hídrico dos solos.

\section{Total das paisagens}

Independente das enormes diferenças de morfologia e regime hídrico, os solos de encosta (EN) e de planície (PL) também diferiram a partir de vários atributos de amostras superficiais (Tabela 3). Inicialmente existiu a diferença marcante na própria paisagem, com a declividade média da PL de $6 \%$ e da EN de $22 \%$ (diferença significativa, $\mathrm{p}<0,01$ ). Dos 10 perfis de solo da PL, oito apresentam relevo plano (declividade $\leq 3 \%$ ), sendo que a média de $6 \%$ de declividade foi influenciada por dois perfis, um Cambissolo Flúvico em cabeceira de drenagem de terraço com $10 \%$ de declividade e um solo construído pela retífica do rio Macacu com fins de saneamento na década de 60 (antropossolo de dique marginal), com $42 \%$ de declividade.

Tabela 2. Coeficiente de correlação linear entre variáveis de amostras superficiais dos solos estudados, incluindo a declividade $(\%)$ local $(\mathrm{n}=48)$.

\begin{tabular}{|c|c|c|c|c|c|c|c|c|c|c|c|c|c|}
\hline & Declividade & $\begin{array}{c}\mathbf{p H} \\
\mathrm{CaCl}_{2}\end{array}$ & $\mathbf{H}+\mathbf{A l}$ & Al & $\mathbf{C a}$ & Mg & $\mathbf{K}$ & SB & CTC & Pas & $\mathrm{CO}$ & $\mathbf{V}$ & m \\
\hline Declividade & 1,00 & & & & & & & & & & & & \\
\hline $\mathrm{pH} \mathrm{CaCl}_{2}$ & $-0,26$ & 1,00 & & & & & & & & & & & \\
\hline $\mathbf{H}+\mathbf{A l}$ & $0,36^{*}$ & $-0,68^{* *}$ & 1,00 & & & & & & & & & & \\
\hline Al & $0,39 * *$ & $-0,73 * *$ & $0,89 * *$ & 1,00 & & & & & & & & & \\
\hline $\mathrm{Ca}$ & $-0,31 *$ & $0,69 * *$ & $-0,48 * *$ & $-0,58 * *$ & 1,00 & & & & & & & & \\
\hline Mg & $-0,12$ & $0,59 * *$ & $-0,34$ & $-0,49 * *$ & $0,77 * *$ & 1,00 & & & & & & & \\
\hline $\mathbf{K}$ & $-0,02$ & 0,17 & $-0,06$ & $-0,03$ & 0,24 & 0,32 & 1,00 & & & & & & \\
\hline $\mathbf{S B}^{1}$ & $-0,25$ & $0,69 * *$ & $-0,45^{* *}$ & $-0,57 * *$ & $0,97 * *$ & $0,90 * *$ & 0,36 & 1,00 & & & & & \\
\hline $\mathrm{CTC}^{1}$ & 0,32 & $-0,56^{* *}$ & $0,97 * *$ & $0,82 * *$ & $-0,25$ & $-0,12$ & 0,03 & $-0,21$ & 1,00 & & & & \\
\hline$P_{\text {as }}^{1}$ & $-0,21$ & 0,35 & $-0,15$ & $-0,18$ & 0,22 & 0,26 & $0,50 * *$ & 0,28 & $-0,09$ & 1,00 & & & \\
\hline $\mathrm{CO}^{1}$ & 0,10 & $-0,05$ & 0,14 & 0,10 & $-0,06$ & $-0,02$ & 0,08 & $-0,04$ & 0,14 & 0,01 & 1,00 & & \\
\hline $\mathbf{V}^{1}$ & $-0,33^{*}$ & $0,77^{*}$ & $-0,65^{* *}$ & $-0,70 * *$ & $0,94 * *$ & $0,82 * *$ & 0,24 & $0,94 * *$ & $-0,45 * *$ & 0,27 & $-0,05$ & 1,00 & \\
\hline $\mathbf{m}^{1}$ & $0,39 * *$ & $-0,79 * *$ & $0,70 * *$ & $0,83 * *$ & $-0,89 * *$ & $-0,76^{* *}$ & $-0,23$ & $-0,89 * *$ & $0,52 * *$ & $-0,32$ & 0,01 & $-0,95 * *$ & 1,00 \\
\hline Argila & $0,52 * *$ & $-0,39 * *$ & $0,58 * *$ & $0,58 * *$ & $-0,19$ & $-0,16$ & 0,22 & $-0,16$ & $0,59 * *$ & $-0,36$ & 0,05 & $-0,34$ & $0,42 * *$ \\
\hline
\end{tabular}

Significativo à: $* \mathrm{p}<0,05, * * \mathrm{p}<0,01 .{ }^{1} \mathrm{SB}=$ soma de bases, $\mathrm{CTC}=$ capacidade de troca catiônica, Pas $=\mathrm{P}$ assimilável, CO $=\mathrm{C}$ orgânico, $\mathrm{V}=$ saturação por bases, $\mathrm{m}=$ saturação por Al. 
Tabela 3. Valores médios, mínimos e máximos $(n=48)$ de atributos de amostras superficiais dos solos estudados agrupados pela unidade de paisagem.

\begin{tabular}{|c|c|c|c|c|c|c|c|}
\hline \multirow{2}{*}{ Atributo } & \multicolumn{4}{|c|}{ Planície $(\mathrm{n}=10)$} & \multicolumn{3}{|c|}{ Encosta $(n=38)$} \\
\hline & Unidade & Média & Mínimo & Máximo & Média & Mínimo & Máximo \\
\hline areia grossa & dag $\mathrm{kg}^{-1}$ & $51 \mathrm{~B}$ & 22 & 73 & $39 \mathrm{~A}$ & 21 & 61 \\
\hline areia fina & dag $\mathrm{kg}^{-1}$ & $21 \mathrm{~B}$ & 12 & 35 & $14 \mathrm{~A}$ & 7 & 26 \\
\hline silte & dag $\mathrm{kg}^{-1}$ & 8 & 3 & 19 & 10 & 1 & 19 \\
\hline Argila & dag $\mathrm{kg}^{-1}$ & $21 \mathrm{~A}$ & 5 & 55 & $37 \mathrm{~B}$ & 20 & 65 \\
\hline P assimilável & dag $\mathrm{kg}^{-1}$ & $3,35 \mathrm{~B}$ & 1,00 & 5,20 & $1,92 \mathrm{~A}$ & 1,00 & 3,80 \\
\hline C orgânico & dag $\mathrm{kg}^{-1}$ & 1,38 & 0,87 & 2,22 & 1,39 & 0,42 & 3,40 \\
\hline $\mathrm{pH} \mathrm{CaCl}_{2}$ & - & $3,9 \mathrm{~b}$ & 3,5 & 4,4 & $3,7 \mathrm{a}$ & 3,3 & 4,5 \\
\hline $\mathrm{Ca}$ & $\mathrm{cmol}_{\mathrm{c}} \mathrm{dm}^{-3}$ & 0,63 & 0,10 & 1,10 & 0,51 & 0,10 & 2,00 \\
\hline $\mathrm{Mg}$ & $\mathrm{cmol}_{\mathrm{c}} \mathrm{dm}^{-3}$ & 0,24 & 0,10 & 0,60 & 0,24 & 0,10 & 1,10 \\
\hline K & $\mathrm{cmol}_{\mathrm{c}} \mathrm{dm}^{-3}$ & $0,09 \mathrm{~b}$ & 0,02 & 0,27 & $0,06 \mathrm{a}$ & 0,01 & 0,12 \\
\hline $\mathrm{Al}$ & $\mathrm{cmol}_{\mathrm{c}} \mathrm{dm}^{-3}$ & $0,85 \mathrm{~A}$ & 0,40 & 1,60 & $1,73 \mathrm{~B}$ & 0,20 & 3,40 \\
\hline $\mathrm{H}+\mathrm{Al}$ & $\mathrm{cmol}_{\mathrm{c}} \mathrm{dm}^{-3}$ & $5,02 \mathrm{~A}$ & 3,00 & 6,70 & $7,77 \mathrm{~B}$ & 3,40 & 12,10 \\
\hline soma de bases & $\mathrm{cmol}_{\mathrm{c}} \mathrm{dm}^{-3}$ & 0,96 & 0,25 & 1,87 & 0,80 & 0,22 & 3,14 \\
\hline capacidade de troca catiônica & $\mathrm{cmol}_{\mathrm{c}} \mathrm{dm}^{-3}$ & $5,98 \mathrm{~A}$ & 3,25 & 8,09 & $8,57 \mathrm{~B}$ & 5,14 & 12,97 \\
\hline saturação por bases (V\%) & $\%$ & 15 & 7 & 25 & 11 & 2 & 42 \\
\hline saturação por Al (m) & $\%$ & $49 \mathrm{a}$ & 22 & 71 & $67 \mathrm{~b}$ & 6 & 92 \\
\hline
\end{tabular}

Médias seguidas de letras na mesma linha apresentam diferença significativa. Letras maiúsculas, $\mathrm{p}<0,01$, e letras minúsculas, $\mathrm{p}<0,05$.

Embora não tenha existido diferença no teor de $\mathrm{CO}$, a CTC dos solos de EN, comandada pela acidez extraível, foi significativamente maior. Poderia se esperar que a média do CO fosse mais elevada na planície, mas o uso da terra predominante (pastagem) parece ter homogeneizado os valores entre as duas unidades de paisagem. A melhor disponibilidade de P assimilável nos solos da PL (embora ainda baixo) relativamente aos de EN, pode estar associada ao ambiente com deficiência de oxigênio dos solos de baixada, que reverte a fixação de $\mathrm{P}$ da fração argila dos solos (Ponnamperuma, 1972; Boschetti et al., 1998), além do menor teor dessa fração nos próprios solos de PL.

Agrupamentos por litotipos no ambiente de encosta

Os valores médios de argila, além de não apresentarem diferença significativa entre os litotipos (Tabela 4), variaram muito dentro de cada grupo. Variou de 20 a $65 \mathrm{dag} \mathrm{kg}^{-1}$ nas amostras do PR e de 20 a $55 \mathrm{dag} \mathrm{kg}^{-1}$ nas amostras do TE. Essa variação denota a importância dos processos morfogenéticos atuantes nestas vertentes, em concomitância com a presença de possíveis diferenças litoestratigráficas (neossomas e paleossomas), comuns em materiais gnáissicos, como os da Formação São Fidelis (Wernick, 2004). Ambos litotipos (PR e TE) deram origem a solos extremamente cauliníticos.
Todos os solos dos dois grupos são distróficos, sendo em média álicos. Os teores médios de $\mathrm{Al}, \mathrm{H}+\mathrm{Al}$ e CTC foram mais altos para os solos do grupo TE do que para os do PR ( $<<0,05)$, e parece ser uma consequência da maior proporção de solos sob floresta em TE.

\section{Agrupamentos por uso atual da terra no ambiente de encosta}

Os valores médios de $\mathrm{CO}$ não diferiram entre os dois grupos de uso da terra (Tabela 5). Os resultados encontrados na literatura são contraditórios em relação as diferenças entre os teores de $\mathrm{C}$ encontrados em solos de floresta e pastagens. Teores de $\mathrm{CO}$ iguais ou superiores nos solos sob pastagem (PA) são atribuídos, em grande parte, ao maior aporte de matéria orgânica proporcionado pelo sistema radicular das gramíneas, em regra bem desenvolvido e bem distribuído e com elevada intensidade de renovação. Teores mais altos de $\mathrm{CO}$ em solos florestais (FL) são atribuídos, em geral, ao maior aporte global de matéria orgânica proporcionada pela floresta, proveniente da deposição contínua e variada de substratos orgânicos e a presença comum de pastagens degradadas como sítios de comparação (Costa et al., 2009; Cardoso et al., 2010). É importante frisar que as pastagens da área do Comperj já estavam sem presençade gado por aproximadamente 
dois anos, quando da realização do estudo, condição que relativamente à uma área pastejada propiciou aumento vertiginoso da biomassa vegetal (com a altura do capim ultrapassando $1,7 \mathrm{~m}) \mathrm{e}$, consequentemente, maior aporte de $\mathrm{CO}$, o que favoreceria o acúmulo de CO no solo (Souza et al., 2009).

Tabela 4. Valores médios, mínimos e máximos $(\mathrm{n}=38)$ de atributos químicos e físicos de amostras superficiais dos solos estudados agrupados por litotipo em solos de encostas.

\begin{tabular}{|c|c|c|c|c|c|c|c|}
\hline \multirow{2}{*}{ Atributo } & \multicolumn{4}{|c|}{ Proterozóico $(n=18)$} & \multicolumn{3}{|c|}{ Terciário $(\mathrm{n}=20)$} \\
\hline & Unidade & Média & Mínimo & Máximo & Média & Mínimo & Máximo \\
\hline areia grossa & dag $\mathrm{kg}^{-1}$ & 38 & 21 & 61 & 41 & 31 & 49 \\
\hline areia fina & dag $\mathrm{kg}^{-1}$ & 12 & 7 & 19 & 15 & 9 & 26 \\
\hline Silte & dag $\mathrm{kg}^{-1}$ & 10 & 1 & 19 & 10 & 2 & 18 \\
\hline Argila & dag $\mathrm{kg}^{-1}$ & 39 & 20 & 65 & 34 & 20 & 55 \\
\hline $\mathrm{P}$ assimilável & dag $\mathrm{kg}^{-1}$ & 1,86 & 1,00 & 3,80 & 1,98 & 1,00 & 3,70 \\
\hline C orgânico & dag $\mathrm{kg}^{-1}$ & 1,45 & 0,42 & 3,40 & 1,33 & 0,42 & 2,22 \\
\hline $\mathrm{pH} \mathrm{CaCl}{ }_{2}$ & - & 3,7 & 3,4 & 4,0 & 3,7 & 3,3 & 4,5 \\
\hline $\mathrm{Ca}$ & $\mathrm{cmol}_{\mathrm{c}} \mathrm{dm}^{-3}$ & 0,48 & 0,10 & 0,90 & 0,53 & 0,10 & 2,00 \\
\hline $\mathrm{Mg}$ & $\mathrm{cmol}_{\mathrm{c}} \mathrm{dm}^{-3}$ & 0,25 & 0,10 & 0,70 & 0,23 & 0,10 & 1,10 \\
\hline K & $\mathrm{cmol}_{\mathrm{c}} \mathrm{dm}^{-3}$ & 0,06 & 0,04 & 0,12 & 0,05 & 0,01 & 0,08 \\
\hline $\mathrm{Al}$ & $\mathrm{cmol}_{\mathrm{c}} \mathrm{dm}^{-3}$ & $1,46 \mathrm{a}$ & 0,40 & 2,20 & $1,99 \mathrm{~b}$ & 0,20 & 3,40 \\
\hline $\mathrm{H}+\mathrm{Al}$ & $\mathrm{cmol}_{\mathrm{c}} \mathrm{dm}^{-3}$ & $7,04 \mathrm{a}$ & 4,60 & 9,70 & $8,43 \mathrm{~b}$ & 3,40 & 12,10 \\
\hline soma de bases & $\mathrm{cmol}_{\mathrm{c}} \mathrm{dm}^{-3}$ & 0,80 & 0,24 & 1,59 & 0,81 & 0,22 & 3,14 \\
\hline capacidade de troca catiônica & $\mathrm{cmol}_{\mathrm{c}} \mathrm{dm}^{-3}$ & $7,84 \mathrm{a}$ & 5,14 & 10,76 & $9,24 \mathrm{~b}$ & 5,55 & 12,97 \\
\hline saturação por bases & $\%$ & 11 & 3 & 26 & 10 & 2 & 42 \\
\hline saturação por Al & $\%$ & 64 & 20 & 90 & 70 & 6 & 92 \\
\hline
\end{tabular}

Médias seguidas de letras na mesma linha apresentam diferença significativa, $p<0,05$.

As amostras de FL apresentaram valor médio de V\% menor que em PA $(\mathrm{p}<0,05)$, ocorrendo o inverso para o valor médio de $\mathrm{m}$ (Tabela 5). Considerando que os teores de $\mathrm{CO}$ não diferiram entre os solos de FL e PA, as diferenças encontradas para estes e outros atributos $(\mathrm{pH}$ $\mathrm{CaCl}_{2}, \mathrm{Ca}, \mathrm{Al}, \mathrm{H}+\mathrm{Al}, \mathrm{CTC}, \mathrm{Pas}$ ), que dependem das cargas da matéria orgânica, parecem ser melhor explicadas pelas diferenças de qualidade do $\mathrm{CO}$ provenientes dos dois usos da terra. A menor acidez da matéria orgânica das pastagens possibilita, por vezes, que essas se apresentem com melhores índices de fertilidade do que em solos sob floresta (Rhoades et al., 2004), embora, localmente, ambos os ambientes apresentem valores de SB e de V\% que refletem uma forte deficiência de nutrientes. Parece que nem o efeito de reciclagem da floresta, nem o efeito residual de possíveis correções e adubações feitas nas áreas de pastagem possibilitam diferenciar essa situação.

A ACP da Figura 2 mostra como os dois grupos de uso da terra responderam à influência das variáveis discutidas anteriormente. O primeiro eixo (respondendo por $52,8 \%$ da variação dos dados) apresentou forte influência dos auto-vetores positivos de Al e CTC e negativos de $\mathrm{pH} \mathrm{CaCl}_{2}, \mathrm{Ca}$ e $\mathrm{V}$. O segundo eixo, representando $17,3 \%$ da variação dos dados, é dominado pela influência do auto-vetor negativo do Pas e, em menor grau, dos auto-vetores positivos da declividade e do teor de silte+argila. Os sítios sob FL e aqueles sob PA formaram, perceptivelmente, dois grupos distintos no plano de ordenamento.

A Figura 3 realça a extrema dependência da CTC dos valores de $\mathrm{H}+\mathrm{Al}$ e como os sítios sob floresta se destacam nesse atributo.

\section{Mineralogia dos solos}

Todos os materiais das amostras de solos selecionados são argilosos e as argilas são de baixa atividade (Tabela 6). Os teores de $\mathrm{Fe}_{2} \mathrm{O}_{3}$ são baixos, mas com diferenças esperadas entre os agrupamentos. Os teores mais baixos foram determinados nas amostras de solos da planície (2,75 e 3,16 dag $\left.\mathrm{kg}^{-1}\right)$, consequência do regime de umidade hidromórfico a semi-hidromórfico da área 
(Kämpf \& Curi, 2000). Na comparação das amostras de encostas, os valores são levemente superiores nos solos do Proterozóico em relação aos do Terciário, resguardando-se a posição de paisagem do terço inferior, onde estes valores, em ambos os litotipos, apresentam-se deplecionados. Assim, no terço inferior de encosta já se observa a ação do regime de maior umidade, que reduz parte das formas cristalinas e retira o Fe livre do sistema.

Tabela 5. Valores médios, mínimos e máximos $(\mathrm{n}=38)$ de atributos químicos e físicos de amostras superficiais dos solos estudados agrupados por uso atual da terra em solos de ambiente de encostas.

\begin{tabular}{|c|c|c|c|c|c|c|c|}
\hline \multirow{2}{*}{ Atributo } & \multirow[b]{2}{*}{ Unidade } & \multicolumn{3}{|c|}{ Floresta $(n=15)$} & \multicolumn{3}{|c|}{ Pastagem $(n=20)$} \\
\hline & & Média & Mínimo & Máximo & Média & Mínimo & Máximo \\
\hline areia grossa & dag $\mathrm{kg}^{-1}$ & 39 & 27 & 48 & 40 & 21 & 61 \\
\hline areia fina & dag $\mathrm{kg}^{-1}$ & 12 & 9 & 18 & 15 & 7 & 26 \\
\hline Silte & dag $\mathrm{kg}^{-1}$ & 11 & 2 & 18 & 9 & 1 & 19 \\
\hline Argila & dag $\mathrm{kg}^{-1}$ & 38 & 30 & 55 & 36 & 20 & 65 \\
\hline P assimilável & dag $\mathrm{kg}^{-1}$ & $2,43 \mathrm{~B}$ & 1,40 & 3,80 & $1,58 \mathrm{~A}$ & 1,00 & 2,60 \\
\hline C orgânico & dag $\mathrm{kg}^{-1}$ & 13,61 & 4,20 & 19,20 & 14,02 & 4,20 & 34,00 \\
\hline $\mathrm{pH} \mathrm{CaCl}{ }_{2}$ & - & $3,5 \mathrm{~A}$ & 3,3 & 4,0 & $3,8 \mathrm{~B}$ & 3,5 & 4,5 \\
\hline $\mathrm{Ca}$ & $\mathrm{cmol}_{\mathrm{c}} \mathrm{dm}^{-3}$ & $0,31 \mathrm{a}$ & 0,10 & 0,70 & $0,63 \mathrm{~b}$ & 0,10 & 2,00 \\
\hline $\mathrm{Mg}$ & $\mathrm{cmol}_{\mathrm{c}} \mathrm{dm}^{-3}$ & 0,21 & 0,10 & 0,70 & 0,26 & 0,10 & 1,10 \\
\hline K & $\mathrm{cmol}_{\mathrm{c}} \mathrm{dm}^{-3}$ & 0,06 & 0,02 & 0,12 & 0,06 & 0,01 & 0,10 \\
\hline $\mathrm{Al}$ & $\mathrm{cmol}_{\mathrm{c}} \mathrm{dm}^{-3}$ & $2,17 \mathrm{~B}$ & 0,60 & 3,40 & $1,45 \mathrm{~A}$ & 0,20 & 2,40 \\
\hline $\mathrm{H}+\mathrm{Al}$ & $\mathrm{cmol}_{\mathrm{c}} \mathrm{dm}^{-3}$ & $9,27 \mathrm{~B}$ & 6,20 & 12,10 & $6,79 \mathrm{~A}$ & 3,40 & 9,70 \\
\hline soma de bases & $\mathrm{cmol}_{\mathrm{c}} \mathrm{dm}^{-3}$ & 0,58 & 0,22 & 1,52 & 0,95 & 0,24 & 3,14 \\
\hline capacidade de troca catiônica & $\mathrm{cmol}_{\mathrm{c}} \mathrm{dm}^{-3}$ & $9,85 \mathrm{~B}$ & 7,37 & 12,97 & 7,74 A & 5,14 & 10,76 \\
\hline saturação por bases & $\%$ & $6 \mathrm{a}$ & 2 & 19 & $13 \mathrm{~b}$ & 3 & 42 \\
\hline saturação por Al & $\%$ & $77 \mathrm{~b}$ & 30 & 92 & $60 \mathrm{a}$ & 6 & 90 \\
\hline
\end{tabular}

Médias seguidas de letras na mesma linha apresentam diferença significativa. Letras maiúsculas, $p<0,01$, e letras minúsculas, $\mathrm{p}<0,05$.
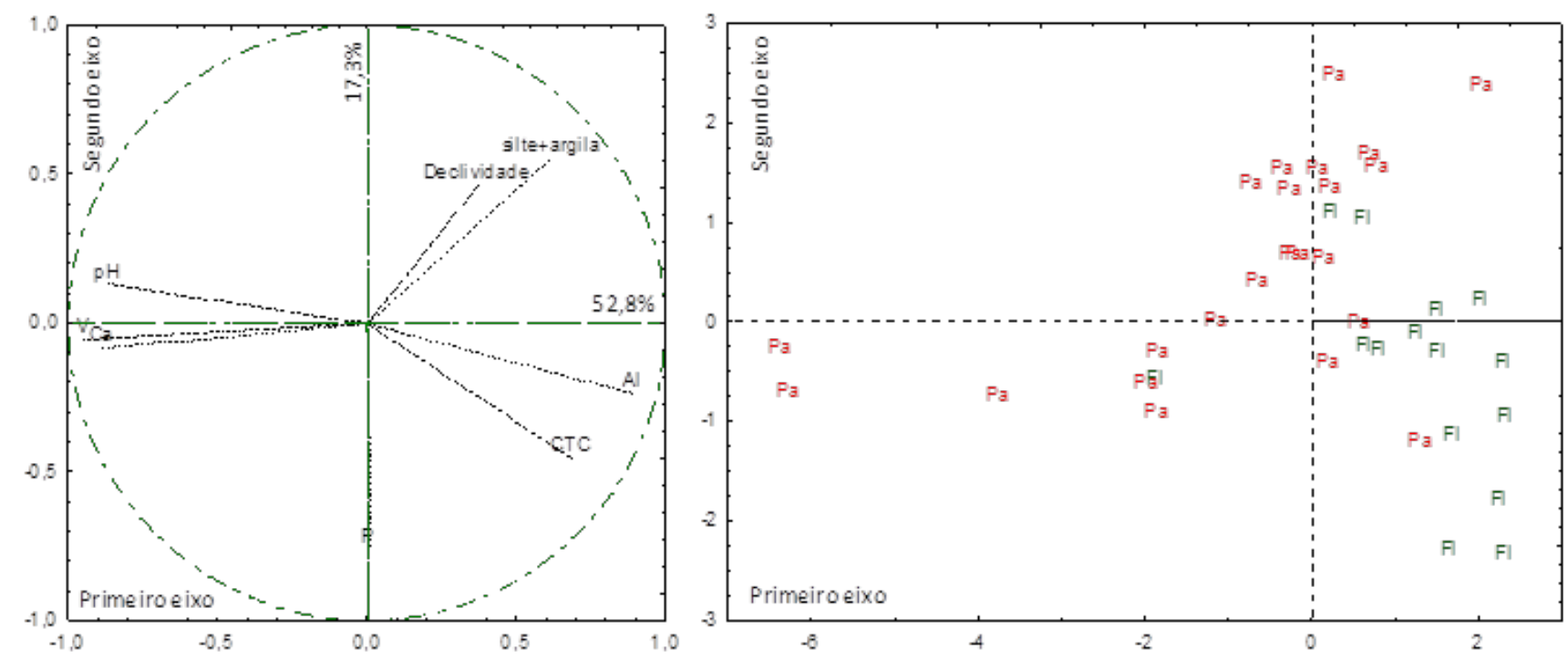

Figura 2. Análise de componentes principais de atributos da paisagem (declividade) e de amostras superficiais dos solos estudados agrupados por uso atual da terra. (A) Círculo de autovetores das variáveis $(\mathrm{pH}=\mathrm{pH} \mathrm{CaCl}, \mathrm{CTC}=$ capacidade de troca catiônica, $\mathrm{V}=$ saturação por bases); (B) Plano de dispersão de pontos. Códigos de cada grupo: $\mathrm{Fl}=$ floresta, $\mathrm{Pa}=$ pastagem. 


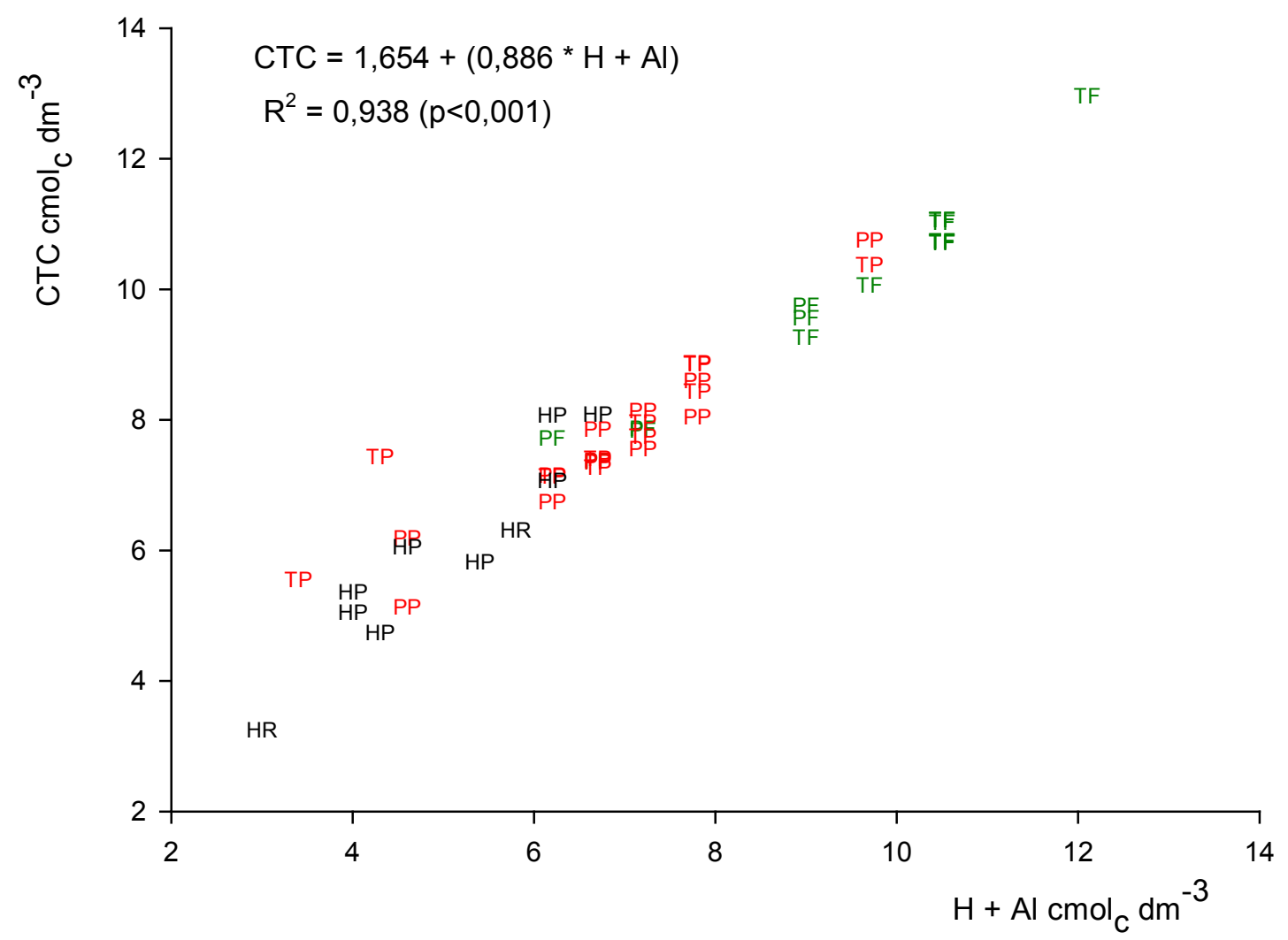

Figura 3. Relação entre acidez extraível $(\mathrm{H}+\mathrm{Al})$ e a capacidade de troca de cátions $(\mathrm{CTC})$. Cores dos códigos: preta $=$ solos de planície, verde $=$ solos de encosta sob floresta, vermelha $=$ solos de encosta sob pastagem. Primeira letra no código: $\mathrm{H}=$ Holoceno, $\mathrm{P}=$ Proterozóico, $\mathrm{T}=$ Terciário. Segunda letra no código: $\mathrm{F}=$ floresta, $\mathrm{P}=$ pastagem, $\mathrm{R}=$ regeneração.

Tabela 6. Dados químicos de interesse aos aspectos mineralógicos de amostras dos horizontes subsuperficiais de perfis de solo selecionados.

\begin{tabular}{|c|c|c|c|c|c|c|c|c|c|c|c|c|c|}
\hline $\begin{array}{c}\text { Posição de } \\
\text { paisagem }\end{array}$ & Horizonte & Profundidade & Argila & CTC & $\begin{array}{c}\text { Atividade } \\
\text { da argila }\end{array}$ & $\mathrm{SiO}_{2}$ & $\mathrm{Al}_{2} \mathrm{O}_{3}$ & $\mathrm{Fe}_{2} \mathrm{O}_{3}$ & $\mathrm{TiO}_{2}$ & $\mathbf{P}_{2} \mathbf{O}_{5}$ & $\mathbf{K i}$ & $\mathbf{K r}$ & $\begin{array}{l}\mathrm{Al}_{2} \mathrm{O}_{3 /} \\
\mathrm{Fe}_{2} \mathrm{O}_{3}\end{array}$ \\
\hline & & $\mathrm{cm}$ & dag $\mathrm{kg}^{-1}$ & \multicolumn{2}{|c|}{$\mathrm{cmol}_{\mathrm{c}} \mathrm{dm}^{-3}$} & \multicolumn{5}{|c|}{----------- dag kg-1 ---------- } & & & \\
\hline \multicolumn{14}{|c|}{ Perfis da encosta do Terciário } \\
\hline terço superior & Bw1 & $34-68$ & 60 & 6,11 & 10,18 & 22,20 & 20,20 & 7,31 & 3,14 & 0,04 & 1,87 & 1,52 & 4,34 \\
\hline terço médio & Bw1 & $27-99$ & 55 & 6,71 & 12,20 & 20,86 & 18,68 & 4,58 & 1,85 & 0,09 & 1,90 & 1,64 & 6,40 \\
\hline terço inferior & Bw1 & $42-79$ & 55 & 7,72 & 14,04 & 20,07 & 16,83 & 3,86 & 2,02 & 0,08 & 2,03 & 1,77 & 6,85 \\
\hline \multicolumn{14}{|c|}{ Perfis da encosta do Proterozóico } \\
\hline terço superior & Bw1 & $41-86$ & 60 & 5,31 & 8,85 & 23,42 & 21,74 & 8,52 & 2,97 & 0,03 & 1,83 & 1,46 & 4,00 \\
\hline terço médio & Bw1 & $47-88$ & 55 & 5,61 & 10,20 & 22,40 & 19,92 & 8,32 & 3,40 & 0,03 & 1,91 & 1,51 & 3,76 \\
\hline terço inferior & Bw1 & $13-47$ & 50 & 5,61 & 11,22 & 19,47 & 16,77 & 5,56 & 3,90 & 0,02 & 1,97 & 1,63 & 4,73 \\
\hline \multicolumn{14}{|c|}{ Perfis da Planície } \\
\hline $\begin{array}{l}\text { bacia de } \\
\text { inundação }\end{array}$ & $\mathrm{Cg} 1$ & $16-36$ & 53 & 8,10 & 15,43 & 19,85 & 18,20 & 2,75 & 2,08 & 0,04 & 1,85 & 1,69 & 10,39 \\
\hline terraço & Bil & $18-47$ & 55 & 7,48 & 13,60 & 18,32 & 17,43 & 3,16 & 2,08 & 0,04 & 1,79 & 1,60 & 8,66 \\
\hline
\end{tabular}

$\mathrm{CTC}=$ Capacidade de troca catiônica; $\mathrm{SiO}_{2}, \mathrm{Fe}_{2} \mathrm{O}_{3}, \mathrm{TiO}_{2}$ e $\mathrm{P}_{2} \mathrm{O}_{3}=$ ataque sulfúrico da terra fina; $\mathrm{Ki}$ = relação molecular $\mathrm{SiO}_{2} / \mathrm{Al}_{2} \mathrm{O}_{3} ; \mathrm{Kr}=$ relação molecular $\mathrm{SiO}_{2} /\left(\mathrm{Al}_{2} \mathrm{O}_{3}+\mathrm{Fe}_{2} \mathrm{O}_{3}\right)$. 
A partir dos difratogramas de R-X (Figura 4), constatou-se uma mineralogia extremamente caulinítica em todos os solos. Os solos de planície apresentam alguma mica, além da dominante caulinita (Figura 4B). Os solos também apresentam goethita em quantidades perceptíveis pelos DRX das amostras não tratadas (resultados não mostrados), mesmo nos perfis da planície. Assim, temos volumes caracterizados por materiais bem intemperizados, mas pouco oxídicos, conforme corroborado pelos valores de Ki e $\operatorname{Kr}$ (Tabela 6).

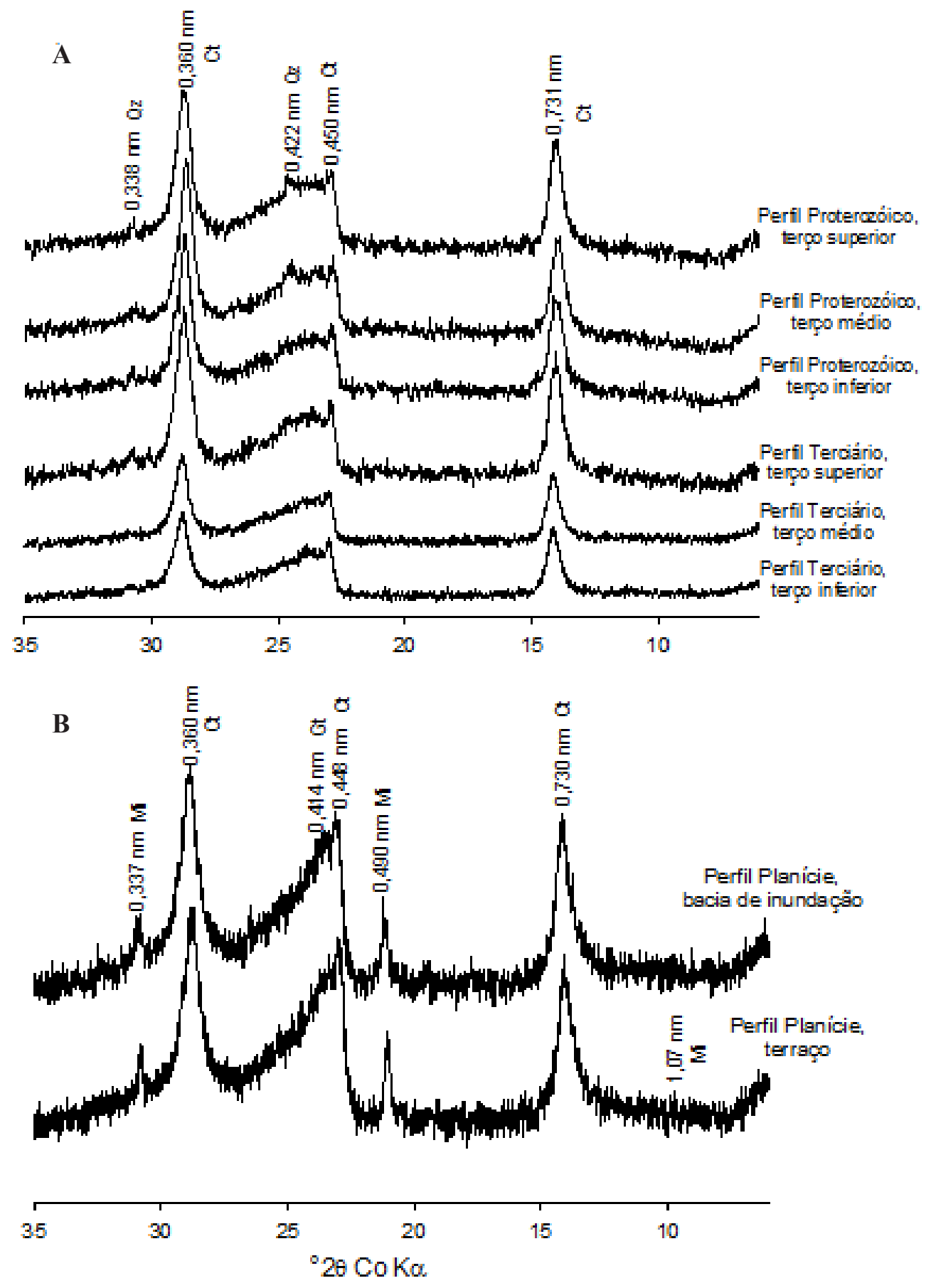

Figura 4. Difratogramas de raios-X de amostras da fração argila desferrificada. A. Perfis das encostas (todas as amostras são de horizontes Bw1); B: Perfis da Planície (perfil da bacia de inundação, horizonte Cg e perfil do terraço, horizonte Big. $\mathrm{Ct}=$ caulinita, $\mathrm{Gb}=$ gibbsita, $\mathrm{Gt}=$ goethita, $\mathrm{Mi}=$ mica, $\mathrm{Qz}=$ quartzo. 
Essa mineralogia dominantemente caulinítica é esperada para os solos desenvolvidos em sedimentos do Terciário associados à Formação Barreiras (Ferreira et al., 1999; Moreau et al., 2006; Corrêa et al., 2008; Gomes et al., 2008) e se repete no presente caso para solos desenvolvidos a partir de depósitos da Formação Macacu (Lima et al., 1996), também de idade Terciária. Para os solos desenvolvidos a partir de sedimentos do Proterozóico, a mineralogia fica dependente das características litoestratigráficas dos materiais gnáissicos da Formação São Fidelis (Wernick, 2004), que apontam grande predominância local de materiais leucocráticos. Nos terços médio e superior das vertentes, onde os teores de Fe foram relativamente mais altos, a cor amarela da maioria dos perfis mostra a predominância de goethita em relação à hematita, sendo que apenas o perfil do terço superior de encosta de elevação do Proterozóico apresenta-se vermelho-amarelado, por influência de hematita. Este perfil foi o que apresentou o maior teor de $\mathrm{Fe}_{2} \mathrm{O}_{3}$ entre os estudados (Tabela 6). Essas características vêm ao encontro da literatura que descreve solos hipo, predominantemente, a mesoférricos, com teores de $\mathrm{Fe}_{2} \mathrm{O}_{3}$ sempre abaixo de $10 \mathrm{dag} \mathrm{kg}^{-1}$, e de cores amareladas a vermelho-amareladas para a região (Projeto RADAMBRASIL, 1983; Carvalho Filho et al., 2000). Aliás, a bicromia dos perfis do PR é bastante comum na área de estudo, com os perfis apresentando cores de horizontes B vermelho-amareladas em profundidade e amareladas imediatamente abaixo do horizonte superficial. Esse fenômeno, chamado de xantização, ocorre como uma consequência dos baixos teores de Fe do material de origem. Para horizontes mais profundos, incluindo o horizonte $\mathrm{C}$ e partes mais profundas do horizonte $\mathrm{B}$, onde a homogeinização da pedogênese $\mathrm{e}$ a atividade dos organismos ainda não alcançaram a sua expressão máxima, a atividade do Fe é relativamente mais alta do que nos horizontes mais superficiais. Nestes horizontes mais profundos a hematita convive com teores já predominantes de goethita. A partir daí, em direção à superfície, uma atividade de Fe mais baixa impõe um pedoambiente com exclusiva manutenção de goethita (Kämpf \& Curi, 2000).

Nas encostas, essa mineralogia muito caulinítica parece influenciar a morfologia de perfis de solos em ambos os litotipos, com a consistência seca muito dura a extremamente dura, aparecendo em subsuperfície no topo do horizonte $\mathrm{B}$ de vários perfis. O fraco desenvolvimento da estrutura (em blocos) e o caráter coeso aparecem em ambos os litotipos e não apenas nos solos desenvolvidos sobre sedimentos Terciários.

\section{Conclusões}

As paisagens de planície e encosta do Comperj apresentam diferenças de comportamento dos atributos químicos do solo superficial, além daquelas associadas ao relevo e ao regime hídrico.

Nas encostas ocorrem diferenças de comportamento entre as amostras superficiais de solo do Comperj, considerando os atributos estudados, em função da origem litotípica e do uso atual da terra.

Os sítios dos dois grupos de uso da terra das encostas (floresta e pastagem) apresentam comportamento diferenciado para vários atributos químicos $\left(\mathrm{pH}, \mathrm{CaCl}_{2}\right.$, Al, Ca, soma de bases, capacidade de troca catiônica, saturação por bases, saturação por Al e P assimilável), sendo a mais perceptível separação dentro do conjunto de sítios estudados.

A mineralogia de todos os solos é extremamente caulinítica, observando-se poucas diferenças entre os grupos de litotipia. Chama a atenção que a consistência muito dura a extremamente dura no topo do horizonte B foi descrita para perfis de solo desenvolvidos em encostas com materiais do Proterozóico e do Terciário.

\section{Referências}

ALMEIDA, F. F. M. The system of continental rifts bordering the Santos Basin, Brazil. Anais Academia Brasileira de Ciências, Rio de Janeiro, v. 48, p. 15-26, 1976.

BARREIRO, J. E. Até onde o olho alcança. Odebrecht Informa. Disponível em: http://www.odebrechtonline.com.br/materias/0240102500/2492/?lang=pt. Acesso em: 31 de março de 2014.

BONNET, A.; RESENDE, A. S.; CURCIO, G. R. Sistemas de plantio e restauração ambiental empregados no Comperj. In: BONNET, A.; RESENDE, A. S.; CURCIO, G. R. Manual de plantio de espécies nativas para o corredor ecológico do Comperj. Seropédica: Embrapa Agrobiologia, 2009. p. 65-98.

BOSCHETTI A., N. G.; QUINTERO G., C. E.; BENAVIDEZ Q., R. A. Caracterização do fator capacidade de fósforo em solos de Entre Rios, Argentina. Revista Brasileira de Ciência do Solo, Campinas, v. 22, p. 95-99, 1998.

CARDOSO, E. L.; SILVA, M. L. N.; SILVA, C. A.; CURI, N.; FREITAS, D. A. F. Estoques de carbono e nitrogênio em solo sob florestas nativas e pastagens no bioma Pantanal. Pesquisa Agropecuária Brasileira, Brasília, DF, v. 45, p. 1028-1035, 2010.

CARVALHO FILHO, A.; LUMBRERAS, J. F.; SANTOS, R. D. Os solos do estado do Rio de Janeiro. Brasília: CPRM, 2000. 
CLAESSEN, M. E. C. (Org.). Manual de métodos de análise de solo. 2. ed. Rio de Janeiro: EMBRAPA-CNPS, 1997. 212 p. (EMBRAPA-CNPS. Documentos, 1).

CORRÊA, M. M.; KER, J. C.; BARRÓN, V.; TORRENT, J.; CURI, N.; TORRES, T. C. P. Caracterização física, química, mineralógica e micromorfológica de horizontes coesos e fragipãs de solos vermelhos e amarelos do ambiente tabuleiros costeiros. Revista Brasileira de Ciência do Solo, Campinas, v. 32, p. 297-313, 2008.

COSTA, O. V.; CANTARUTTI, R. T.; FONTES, L. E. F.; COSTA, L. M.; NACIF, P. G. S.; FARIA, J. C. Estoque de carbono do solo sob pastagem em área de tabuleiro costeiro no sul da Bahia. Revista Brasileira de Ciência do Solo, Campinas, v. 33, p. 1137-1145, 2009.

CURCIO, R. C.; DEDECEK, R. A.; BONNET, A. Geologia, geomorfologia e pedologia. In: BONNET, A.; RESENDE, A. S.; CURCIO, G. R. Manual de plantio de espécies nativas para o "Corredor ecológico COMPERJ". Seropédica: Embrapa Agrobiologia; Colombo: Embrapa Florestas; Rio de Janeiro: Embrapa Solos, 2009. p.1-26.

FELLER, C.; BEARE, M. H. Physical control of soil organic matter dynamics in the tropics. Geoderma, Amsterdam, v. 79, p. 69-116, 1997.

FERREIRA, M. M.; FERNANDES, B.; CURI, N. Mineralogia da fração argila e estrutura de Latossolos da região Sudeste do Brasil. Revista Brasileira de Ciência do Solo, Campinas, v. 23, p. 507-514, 1999.

GOMES, J. B. V.; BOLFE, E. L.; CURI, N.; FONTES, H. R.; BARRETO, A. C.; VIANA, R. D. Variabilidade espacial de atributos de solos em unidades de manejo em área piloto de produção integrada de coco. Revista Brasileira de Ciência do Solo, Campinas, v. 30, p. 1021-1030, 2008.

KÄMPF, N.; CURI, N. Óxidos de ferro: indicadores de ambientes pedogênicos e geoquímicos. Tópicos em Ciência do Solo, v. 1, p. 107-138, 2000.

LIMA, M. R.; CABRAL JUNIOR, M.; STEFANI, F. L. Palinologia de sedimentos da Formação Macacu - rifte da Guanabara, Terciário do Estado do Rio de Janeiro, Brasil. Anais da Academia Brasileira de Letras, v. 68, p. 531-543, 1996.

MEHRA, O. P.; JACKSON, M. L. Iron oxide removal from soils and clays by a dithionite-citrate system buffered with sodium bicarbonate. Clays and clay minerals, New York, v. 7, p. 317-327, 1960.
MOREAU, A. M. S. dos S.; COSTA, L. M.; KER, J. C.; GOMES, F. H. Gênese de horizonte coeso, fragipã e duripã em solos do tabuleiro costeiro do sul da Bahia. Revista Brasileira de Ciência do Solo, Campinas, v. 30, p. 1021-1030, 2006.

PONNAMPERUMA, F. N. The chemistry of submerged soils. Advances in Agronomy, New York, v. 24, p. 29-96, 1972.

PROJETO RADAMBRASIL. Levantamento de recursos naturais, 32. Folha SF.23/24 Rio de Janeiro/Vitória: geologia, geomorfologia, pedologia, vegetação e uso potencial da terra. Rio de Janeiro: Ministério das Minas e Energia, 1983. 780 p.

RESENDE, A. S.; CURCIO, G. R.; CAMPELlO, E. F. C.; BONNET, A. Caracterização climática, etapas e recomendações para implantação da porção leste do "Corredor Ecológico Comperj". In: BONNET, A.; RESENDE, A. S.; CURCIO, G. R. Manual de plantio de espécies nativas para o corredor ecológico do Comperj. Seropédica: Embrapa Agrobiologia, 2009. p. 111-144.

RELATÓRIO DE IMPACTO AMBIENTAL - RIMA. Complexo Petroquímico do Rio de Janeiro. Concremat Engenharia. Disponível em: http://www.petrobras.com.br/pt/nossas-atividades/principaisoperacoes/refinarias/complexo-petroquimico-do-rio-de-janeiro.htm. Acesso em: 31 de março de 2014.

RHOADES, C. C.; MILLER, S. P.; SHEA, M. M. Soil properties and soil nitrogen dynamics of prairie-like forest openings and surrounding forests in Kentucky's Knobs region. The American Midland Naturalist, Notre-Dame, v. 152, p. 1-11, 2004.

SOUZA, E. D.; COSTA, S. E. V. G. de A.; ANGHINONI, I.; CARVALHO, P. C. de F.; ANDRIGUETI, M.; CAO, E. Estoques de carbono orgânico e de nitrogênio no solo em sistema de integração lavourapecuária em plantio direto, submetido a intensidades de pastejo. Revista Brasileira de Ciência do Solo, Campinas, v. 33, p. 1829-1836, 2009.

WERNICK, E. Rochas magmáticas: conceitos fundamentais e classificação modal, química, termodinâmica e tectônica. São Paulo: UNESP, 2004. 655 p.

ZINN, Y. L.; BIGHAM, J. M.; RESCK, D. V. S. Edaphic controls on soil organic carbon retention in the brazilian cerrado: texture and mineralogy. Soil Science Society of American Journal, Madison, v. 71, p. 1204-1214, 2007. 
